\title{
COMPLICATIONS FOLLOWING MEDIAL OPENING WEDGE OSTEOTOMY OF THE KNEE: RETROSPECTIVE STUDY
}

Wilson Alves de Mello Junior ${ }^{1}$, Luciano Rodrigo Peres Arruda ${ }^{2}$, André Muller Coluccini ${ }^{2}$, Rodrigo Pereira da Silva Nunes ${ }^{2}$, Márcio do Amaral Camargo Pedro², Márcio Regis de Souza ${ }^{2}$, José Luis Amin Zabeu ${ }^{3}$

\section{ABSTRACT}

Objective: To retrospectively survey the most frequent complications from medial opening wedge high-tibial osteotomy. This procedure is becoming increasingly important in treating knee arthrosis, as one of the options for young and active patients. Despite satisfactory results and its benefits, it is not a complication-free procedure. Methods: All cases of medial opening wedge high-tibial osteotomy above the tibial tubercle with fixation using a Puddu plate that were performed at the Celso Pierro Hospital and Maternity Hospital, Pontifical Catholic University of Campinas (PUC-Campinas) and the Wilson Mello Institute, Campinas, between October 1, 1987, and October 30, 2008, were evaluated retrospectively. Patients with less than 12 months of follow-up or incomplete medical files, and those who underwent bilateral osteotomy, were excluded. Results: Out of the 67 cases evaluated, 55 were males and 12 were females, with a mean age of 49.5 years. The mean wedge size was $10.15 \mathrm{~mm}$ and the most common complications were moderate to severe pain (13.04\%), stiffness $(6.52 \%)$, material breakage (4.4\%), intraoperative fracture of the lateral cortical bone (4.4\%) and infection (4.4\%). It was observed that patients with delayed consolidation of the osteotomy had a greater chance of presenting complications $(p<0.05)$. Conclusion: Complications from medial wedge osteotomy are more frequent when associated with delayed consolidation.

Keywords - Knee; Osteotomy; Postoperative Complications; Retrospective Studies.

\section{INTRODUCTION}

High tibial osteotomy (HTO) is gaining increasing space for knee arthrosis treatment, as one of the options for young and active patients. Many surgical techniques have been described since the first description by Jackson in $1958^{(1)}$, such as dome osteotomy $^{(1,2)}$, medial opening wedge ${ }^{(3)}$, lateral closure wedge $^{(4)}$ and Ilizarov ${ }^{(5)}$, among others, and each of them has its advantages and disadvantages. Medial opening wedge HTO above the tubercle is becoming more popular as a method that presents few complications $^{(6,7)}$, in comparison with other methods, and as a correction technique of greater precision $^{(8)}$. Its advantages include: 1) lack of need for lateral dissection and/or osteotomy of the fibula, thereby diminishing the risk of praxis of the common fibular nerve; 2) provision of limb stretching, given that in arthrosis there is diminution of the joint space, with relative shortening; 3) the results from angular correction described in the literature are superior to those from

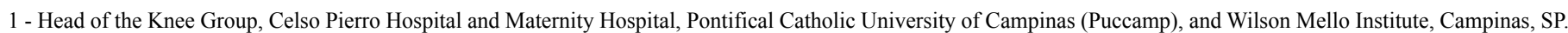

2 - Attending Physician in the Knee Group, Celso Pierro Hospital and Maternity Hospital, Pontifical Catholic University of Campinas (Puccamp), SP.

3 - Head of the Department of Orthopedics, Celso Pierro Hospital and Maternity Hospital, Pontifical Catholic University of Campinas (Puccamp), SP.

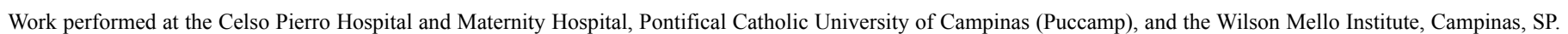
Correspondence: Luciano Rodrigo Peres Arruda - Rua Tavares Bastos 68 - Apto 132 - 05012-020 São Paulo, SP. E-mail: peresluciano@hotmail.com

Work received for publication: June 10, 2010; accepted for publication: August 23, 2010. 
using a lateral closure wedge; 4) provision of proximal tibial correction that is more anatomical, thus minimizing the difficulty for future arthroplasty; and other advantages presented in Table 1 .

Table 1 - Complications described from osteotomies.

\begin{tabular}{|c|c|}
\hline Medial opening wedge & Lateral closure wedge \\
\hline Infection & Infection \\
\hline DVT & DVT \\
\hline Abnormality of the tibial slope & PTE \\
\hline Paresthesia of the fibular nerve & Paralysis of the fibular nerve \\
\hline Pain at the donor site (bone graft) & $\begin{array}{c}\text { Paralysis of the long extensor of } \\
\text { the hallux }\end{array}$ \\
\hline $\begin{array}{c}\text { Fracture of the lateral cortex of } \\
\text { the tibia }\end{array}$ & Fracture of the tibial plateau \\
\hline Delayed consolidation & Delayed consolidation \\
\hline Pseudarthrosis & Pseudarthrosis \\
\hline Loss of correction & Loss of correction \\
\hline Vascular lesion & Lesion of the popliteal artery \\
\hline Pain in the implant & Failure of the material \\
\hline Compartmental syndrome & Compartmental syndrome \\
\hline Necrosis of the tibial plateau & Varus instability \\
\hline Low patella & Pseudarthrosis of the fibula \\
\hline Sudeck syndrome & Hematoma \\
\hline \multicolumn{2}{|l|}{ Septic arthritis } \\
\hline \multicolumn{2}{|l|}{ Osteomyelitis } \\
\hline Misalignment & \\
\hline
\end{tabular}

Despite these benefits, medial opening HTO presents some important complications ${ }^{(3,9-12)}$ and details of the surgical technique that directly influence the final results from the procedure. Orthopedists need to be aware of these complications, both to avoid them and to follow up the treatment in operated cases.

Thus, the objective of this study was to describe the most frequent complications from medial opening wedge HTO, from retrospective observation on the patients operated.

\section{MATERIALS AND METHODS}

A retrospective assessment was made on all the patients who underwent medial opening wedge HTO above the tubercle that was fixed using a Puddu plate (Figure 1), performed between October 1, 1987, and October 30, 2008, at the Celso Pierro Hospital and Maternity Hospital, Pontifical Catholic University of

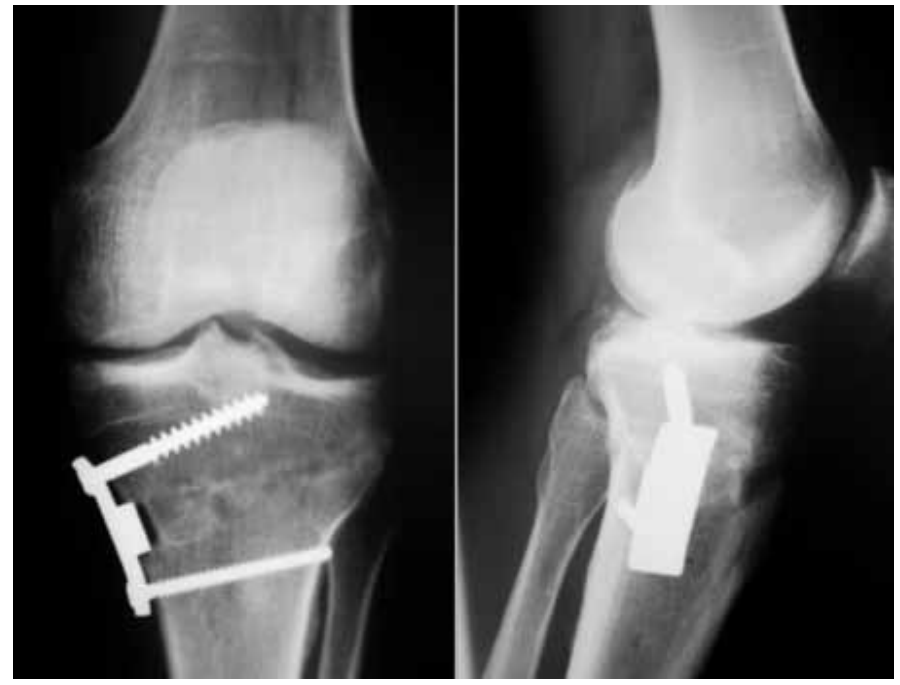

Figure 1 - Medial open wedge osteotomy fixed with Puddu plate.

Campinas (PUC-Campinas) and at the Wilson Mello Institute, in Campinas.

Patients who had had less than 12 months of follow-up, who had incomplete medical files, who had undergone bilateral osteotomy and who did not satisfy the criteria described above were excluded from the study.

The data were gathered into electronic medical files, through the Doctor's Office and MV Health Systems software, with assessment of the following variables: age, sex, side, wedge size, preoperative varus angle, diagnosis, use of bone graft, range of motion (ROM) before and after, time taken to reach consolidation, occurrence of complications like pain, praxis, deep vein thrombosis (DVT), pulmonary thromboembolism (PTE), delayed consolidation, pseudarthrosis, joint stiffness, infection, breakage of the lateral cortex during or after the operation, intra-articular fracture and compartmental syndrome.

Post-surgical pain was assessed 12 months after the surgical procedure by means of a visual analogue scale (VAS). Lack of radiographic signs according to Staubli's criteria ${ }^{(13)}$ less than six months after the surgical procedure was taken to be delayed consolidation and absence of these signs more than six months after the surgery was taken to be pseudarthrosis.

To test whether occurrences of complications in general were influenced by any of the above variables, Student's t test was used at the significance level of 5\%. All the analyses were performed using the R software (www.r-project.org). 


\section{RESULTS}

Seventy-two patients who underwent medial opening wedge HTO over the study period were identified. Six of them were excluded because of incomplete medical files. Thus, a sample of 67 patients and 67 knees was assessed: 12 females (17.9\%) and 55 males (82.1\%), all fixed using a wedge-type (Puddu) plate. The mean age was 49.5 years, with a range from 17 to 74 years (Figure 2).

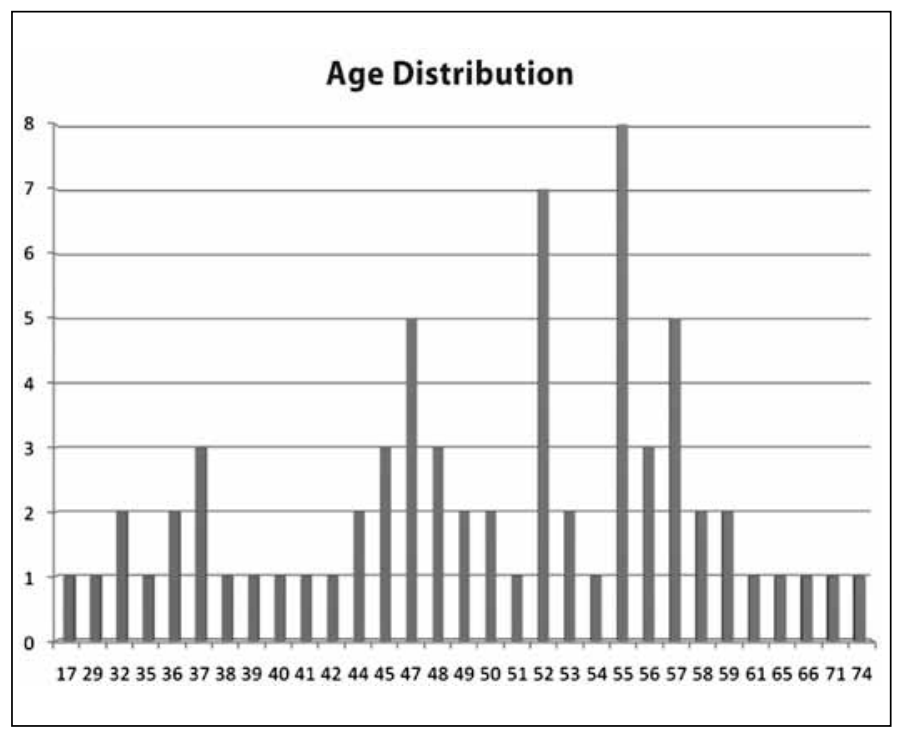

Figure 2 - Age distribution in years.

The commonest diagnosis was idiopathic medial arthrosis, which occurred in 29 patients (43.29\%), followed by post-traumatic arthrosis, in 26 patients. Table 2 presents the frequency of occurrence of each diagnosis in the sample.

The mean value for the wedge was $10.15 \mathrm{~mm}$, with a range from $5 \mathrm{~mm}$ to $17.5 \mathrm{~mm}$. The mean preoperative varus angle was 9.2 degrees (ranging from 2 to 16 degrees) and the mean time taken to reach consolidation was 4.4 months.

Table 2 - Frequencies of the diagnoses.

\begin{tabular}{c|c}
\hline Diagnosis & Frequency \\
\hline Idiopathic primary arthrosis & $29(43.29 \%)$ \\
\hline Post-traumatic arthrosis & $26(38.81 \%)$ \\
\hline Post-meniscectomy arthrosis & $9(13.43 \%)$ \\
\hline Post-fracture arthrosis due to failure & $2(2.98 \%)$ \\
\hline $\begin{array}{c}\text { Desiccating post-osteochondritis } \\
\text { arthrosis }\end{array}$ & $1(1.49 \%)$ \\
\hline
\end{tabular}

Rev Bras Ortop. 2011;46(1):64-8
In relation to the complications, the most frequent of these was postoperative pain, which was found in 30 patients (65.2\%) 12 months after the surgery, as assessed using the VAS. Among these patients, only the cases with moderate or severe pain were considered to represent complications, comprising six cases (13.04\%). Among the patients with moderate pain, two $(6.66 \%)$ had pain caused by mechanical irritation of the plate on the pes anserine, which was resolved after removing the synthesis material. Table 3 shows the distribution of the VAS: most of the patients (22; $78.57 \%$ ) had scores of between 1 and 3, i.e. characterized as presenting mild pain. Only one patient (3.57\%) continued to present a condition of severe pain after the operation. In this case, total arthroplasty had been performed two years after osteotomy.

Table 3 - Distribution of patients presenting pain 12 months after the surgery (analogue pain scale).

\begin{tabular}{c|c}
\hline Visual analogue scale & Frequency \\
\hline Mild pain (1-3) & $22(78.57 \%)$ \\
\hline Moderate pain (4-7) & $5(17.85 \%)$ \\
\hline Intense pain (8-10) & $1(3.57 \%)$ \\
\hline Total & $28(100 \%)$ \\
\hline
\end{tabular}

The second most frequent complication was joint stiffness, which occurred in three patients $(6.52 \%)$ and was characterized as diminished ROM after the operation. The remainder of the complications are demonstrated in Table 4.

The result from the sample was that 47 patients had some type of complication, and these data were subjected to statistical tests to investigate whether any of the variables studied had statistical significance with regard to influencing occurrences of complications. No significance was found in relation to the variables of age $(p=0.541)$, wedge size $(p=0.696)$ or preoperative varus angle $(\mathrm{p}=0.922)$. The only variable that presented an influence on the occurrence of complications was the time taken to reach consolidation $(p=0.046)$, i.e. the longer it took for consolidation to be achieved, the greater the likelihood was that the patient would develop some type of complication. 
Table 4 - Distribution of the frequencies of complications.

\begin{tabular}{c|c}
\hline Complication & Frequency \\
\hline $\begin{array}{c}\text { Moderate and intense postoperative } \\
\text { VAS }\end{array}$ & $6(13.04 \%)$ \\
\hline Breint stiffness & $3(6.52 \%)$ \\
\hline Intraoperative lateral cortex fracture & $2(4.4 \%)$ \\
\hline Postoperative lateral cortex fracture & $2(4.4 \%)$ \\
\hline Intra-articular fracture & $1(2.2 \%)$ \\
\hline Infection & $2(4.4 \%)$ \\
\hline Pseudarthrosis & $2(4.4 \%)$ \\
\hline Deep vein thrombosis & $2(4.4 \%)$ \\
\hline Pulmonary embolism & $2(4.4 \%)$ \\
\hline Compartmental syndrome & $0(0.0 \%)$ \\
\hline Neuropraxia & $0(0.0 \%)$ \\
\hline \begin{tabular}{c} 
Bual \\
\hline
\end{tabular} & $0(0.0 \%)$ \\
\hline
\end{tabular}

\section{DISCUSSION}

From assessing the data, we noted that there was greater incidence of male patients undergoing HTO $(82.1 \%)$, with a mean age of 49.5 years, and with idiopathic medial arthrosis (43.29\%) as the main etiology. In the literature, data similar to these can be found ${ }^{(3,9)}$, thus showing the profile of patients indicated for this type of procedure.

Out of the total number of patients, 47 presented some type of complication, of whom 33 presented residual pain as the main complaint. It is important to emphasize that pain was assessed using the VAS 12 months after the procedure. One patient $(3.57 \%)$ presented intense pain and five patients (17.85\%) presented moderate pain, but the great majority (78.57\%) of the patients reported slight residual pain that did not impede them from performing their activities of daily living. We did not find any study in the literature that itemized residual pain as a postoperative complication, and we believe that these results, together with the patients' ages and degree of arthrosis, may contribute towards the indication for the procedure.

Complications after HTO with an opening wedge have been described in the literature. Miller and Downie $^{(9)}$ reported a complication rate of $36.9 \%$, of which $15.2 \%$ was loss of correction; $4.3 \%$ fracturing of the lateral cortex during the operation; $4.3 \%$ fracturing of the lateral cortex after the operation; 4.3\% DVT; $4.3 \%$ delayed consolidation; and $4.3 \%$ pain due to the implant.

$\mathrm{Spahn}^{(3)}$ reviewed 85 osteotomies, of which 55 were fixed with a medial Puddu plate, and found that $43.6 \%$ presented complications (two with hematomas, four with infection, nine with synthesis material failure, eight with lateral cortex fractures and one with DVT).

In the present study, we found synthesis material failure in $4.4 \%$ of the cases and lateral cortex fracture also in $4.4 \%$ of the cases, which was similar to findings in the literature. Several studies have correlated lateral cortex fractures with instability and development of pseudarthrosis or loss of correction $^{(3,10,11)}$. Our study found pseudarthrosis in $4.4 \%$ and joint stiffness in $6.52 \%$, which correlated directly with the lateral cortex fracture rate and longer duration of postoperative immobilization.

Therefore, a meticulous surgical technique must be used to avoid breakage of the lateral cortex, and stable fixation must be used. Paccola et $\mathrm{al}^{(14)}$ described the use of a lateral cortical screw to fix the osteotomy when this breakage occurred, in order to avoid instability and thus provide faster consolidation and early joint mobility, thereby giving rise to a lower risk of complications.

Our rates of infection (4.4\%), DVT (4.4\%) and intra-articular fracture $(4.4 \%)$ were similar to what has been described in the literature. These are complications that depend on the technique and the duration of postoperative immobilization. There were no cases of pulmonary embolism, neuropraxia or compartmental syndrome.

From the statistical analysis, it could be seen that the only variable studied that was relevant to the complication rate was the time taken to reach consolidation $(p=0.046)$. In other words, the longer the time taken for the osteotomy to consolidate was, the greater the likelihood was that complications would develop. From analysis on the parameters separately, residual pain and stiffness (which were responsible for the majority of the 
complications) were closely related to the time taken to reach consolidation, just like fatigue and breakage of the synthesis material.

Because this was a retrospective study, with a relatively short follow-up (12 months), we are aware of its limitations. New prospective studies with longer follow-up and comparing different fixation methods are needed to investigate the complications from osteotomies.

\section{CONCLUSION}

Medial opening wedge HTO is a procedure that is not free from complications. The most frequent complication in the present study was moderate and severe postoperative pain, followed by other complications (stiffness, pseudarthrosis, infection, breakage of synthesis material and lateral cortex failure). All of these were mainly related to the time taken to reach consolidation of the osteotomy.

\section{REFERENCES}

1. Jackson J. Osteotomy for osteoarthritis of the knee. Proceedings of the Sheffield Regional Orthopaedic Club. J Bone Joint Surg Br. 1958;40:826.

2. Takahashi T, Wada Y, Tanaka M, Iwagawa M, Ikeuchi M, Hirose D, et al. Domeshaped proximal tibia osteotomy using percutaneous drilling for osteoarthritis of the knee. Arch Orthop Trauma Surg. 2000;120(1-2):32-7.

3. Spahn G. Complications in high tibial (medial opening wedge) osteotomy. Arch Orthop Trauma Surg. 2003;124(10):649-53.

4. Catagni M, Guerreschi F, Ahmad T, Cattaneo R. Treatment of genu varum in medial compartment osteoarthritis of the knee using the llizarov method. Orthop Clin North Am. 1994;25(3):509-14.

5. Conventry M. Osteotomy of the upper portion of the tibia for degenerative arthritis of the knee. A preliminary report. J Bone Joint Surg Am. 1965;47:984-90.

6. Koshino T, Murase T, Saito T. Medial opening-wedge high tibial osteotomy with use of porous hydroxyapatite to treat medial compartment osteoarthritis of the knee. J Bone Joint Surg Am. 2003;85(1):78-85.

7. Warden SJ, Morris HG, Crossley KM, Brukner PD, Bennell KL. Delayed- and non-union following opening wedge high tibial osteotomy: surgeons' results from 182 completed cases. Knee Surg Sports Tramatol Arthosc. 2005;13(1):34-7.

8. Hernigou P, Medevielle D, Debeyre J, Goutallier D. Proximal tibial osteotomy for osteoarthritis with varus deformity. A ten to thirteen-year follow-up study. J Bone Joint Surg Am. 1987;69(3):332-54.

9. Miller BS, Downie B, McDonough B, Wojtys EM. Complications after medial opening wedge high tibial osteotomy. Arthroscopy. 2009;5(6):639-46.

10. Niemeyer P, Koestler W, Kaehny C, Kreuz PC, Brooks CJ, Strohm PC, et al. Two-year results of open-wedge high tibial osteotomy with fixation by medial plate fixator for medial compartment arthritis with varus malalignment of the knee. Arthroscopy. 2008;24(7):796-804.

11. Van den Bekerom MPJ, Patt TW, Kleinhout MY, Van der Vis HM, Albers GHR. Early complications after high tibial osteotomy: a comparison of two techniques. J Knee Surg. 2008;21(1):68-74.

12. Wright JM, Crockett HC, Slawski DP, Madsen MW, Windsor RE. High tibial osteotomy. J Am Acad Orthop Surg. 2005;13(4):279-89.

13. Staubli AE. Radiologische heilungsvorgänge nach öffnender kniegelenksnaher tibiaosteotomie. In: Lobenhoffer AG, editor. Kniegelenksnaher osteotomien. New York: Georg Thieme Verlag; 2006. p. 67-78.

14. Paccola AJ, Fagagnolo F. Open-wedge high tibial osteotomy: a technical trick to avoid loss of reduction of the opposite cortex. Knee Surg Sports Traumatol Arthrosc. 2005;13(1):19-22. 